\title{
Population-attributable fractions in gastric cancer risk factors: the necessity to focus on Helicobacter pylori infection
}

\section{To the Editor:}

Although cancer is known to be, in part, genetically determined, most malignancies evolve as a consequence of interactions between the host and environmental/ behavioral/lifestyle factors [1]. Recently, Danaei and colleagues [2] published a comprehensive review article proposing that mortality from 11 major cancers is largely attributable to nine factors, working singly or in combination: overweight and obesity (high body mass index); low fruit and vegetable intake; physical inactivity; smoking; alcohol use; unsafe sex; urban air pollution; indoor smoke from household use of solid fuels; and contaminated injections in healthcare settings. The implication is that most cancers are theoretically preventable if we could modulate exposure to the respective factors that affect specific organs.

In regard to infection-related malignancies, the focus was solely on hepatocellular carcinoma, with contaminated injections (therefore hepatitis $\mathrm{B} / \mathrm{C}$ viruses) concluded to be responsible for $18 \%$ overall, and cancer of the cervix uteri, where the population-attributable fraction (PAF\%) due to unsafe sex and, thus, the human papilloma virus, was calculated to be $100 \%$. However, there are other organs in which infections are well known to play major roles; in particular, the stomach.

Danaei et al. computed PAF\%s for gastric cancer attributable to smoking and low fruit and vegetable intake to be $27 \%$ in low- and middle-income countries and $34 \%$ in high-income areas. Observational studies, including our own experience with cross-country comparisons, have indicated that Helicobacter pylori (H. pylori) infection is essentially related to stomach cancer, at least to cancers in the noncardia zone [3-8]. In fact, similar to the $\mathrm{PAF} \%$ for cancer of the cervix uteri, the $\mathrm{PAF} \%$ for noncardia gastric adenocarcinoma is

Offprint requests to: $\mathrm{S}$. Tokudome

Received: May 26, 2006 / Accepted: May 30, 2006 conceivably $100 \%$ attributable to $H$. pylori infection, acting in combination with other environmental/behavioral/lifestyle factors [1,9].

Accordingly, we feel that more stress should be placed on categorizing stomach cancer as one of the infection-related malignancies. Prevention of $H$. pylori infection and eradication measures appear to be crucial for the prevention and control of noncardia gastric cancer.

$$
\begin{array}{r}
\text { Shinkan Tokudome, Akihiro Hosono, } \\
\text { and Sadao Suzuki } \\
\text { Department of Health Promotion and } \\
\text { Preventive Medicine, Nagoya City University } \\
\text { Graduate School of Medical Sciences, } \\
\text { Nagoya 467-860, Japan }
\end{array}
$$

\section{References}

1. World Cancer Research Fund/American Institute for Cancer Research. Food, nutrition and the prevention of cancer: a gobal perspective. Washington, DC: American Institute for Cancer Research; 1997.

2. Danaei G, van der Hoorn S, Lopez AD, Murray CJ, Ezzati M, Comparative Risk Assessment Collaborating Group (Cancers). Causes of cancer in the world: comparative risk assessment of nine behavioural and environmental risk factors. Lancet 2005;366:178493.

3. Uemura N, Okamoto S, Yamamoto S, Matsumura N, Yamaguchi $\mathrm{S}$, Yamakido M, et al. Helicobacter pylori infection and the development of gastric cancer. N Engl J Med 2001;345:784-9.

4. Graham KS, Graham DY. H pylori-associated gastrointestinal diseases. 2nd Ed. Newtown, PA: Handbooks in Health Care Co; 2002.

5. Brenner H, Arndt V, Stegmaier C, Ziegler H, Rothenbacher D. Is Helicobacter pylori infection a necessary condition for noncardia gastric cancer? Am J Epidemiol 2004;159:252-8.

6. Ohata H, Kitauchi S, Yoshimura N, Mugitani K, Iwane M, Nakamura H, et al. Progression of chronic atrophic gastritis associated with Helicobacter pylori infection increases risk of gastric cancer. Int J Cancer 2004;109:138-43.

7. Tokudome S, Soeripto, Triningsih FXE, Ananta I, Suzuki S, Kuriki $\mathrm{K}$, et al. Rare Helicobacter pylori infection as a factor for the very 
low stomach cancer incidence in Yogyakarta, Indonesia. Cancer Lett 2005;219:57-61.

8. Tokudome S, Samsuria WD, Soeripto, Triningsih FXE, Suzuki S, Hosono A, et al. Helicobacter pylori infection appears essential for stomach carcinogenesis: observations in Semarang, Indonesia. Cancer Sci 2005;96:873-5.
9. IARC. Monographs on the evaluation of carcinogenic risks to humans. Tobacco smoke and involuntary smoking. Vol. 83. Lyon: IARC; 2004. 